of people with rheumatic diseases and fatigue. The current intervention was developed as a supplement to medical treatment to strengthen coping and quality of life, and reducing fatigue, depression and pain.

Methods: People with inflammatory rheumatic diseases and fatigue were recruited for $6-9$ sessions of cognitive therapy sessions, in addition to treatment as usual at a rheumatology outpatient clinic in Norway. The intervention aimed at reducing fatigue, depression and pain, consisted of four main elements; understanding fatigue, assessment and activity planning, mental and cognitive self-help skills. The project was developed, and data collected at the rheumatology outpatient clinic at Diakonhjemmet Hospital in 2014-2016.

Results: This pilot project recruited 40 people with inflammatory rheumatic disease from a rheumatologic outpatient clinic in Norway. Participants had a disease duration of mean 14 years, they were mainly women $(n=36)$ with a mean age of 45 (Standard Deviation $=10$ ) years (Table 1). Repeated ANOVA analyses and Paired t-tests showed promising statistically significant changes on a group level for fatigue and depression, not for pain (Table 2).

Table 1. Demographic data of included patients $(n=40)$

\begin{tabular}{lc}
\hline $\mathrm{N}=40$ & Mean values \\
\hline Age (SD) & $45(10)$ \\
Women (men) & $36(4)$ \\
Disease duration (years) & $14(11)$ \\
\hline
\end{tabular}

Conclusions: This pilot project supports the idea of conducting a trial on the effectiveness of a brief cognitive therapy intervention for people with inflammatory rheumatic diseases and fatigue. ANOVA analyses and Paired t-tests showed promising statistically significant changes on a group level for fatigue and depression, but not for pain, whether these changes are clinically meaningful, and if there is a difference, compared to treatment as usual remains to be explored.

Acknowledgements: This project would not have been possible without the support from the national patient organization, through a grant from the Norwegian ExtraFoundation for Health and Rehabilitation. We acknowledge patients who contributed to this project and the staff at the rheumatological outpatient clinic at Diakonhjemmet Hospital.

Disclosure of Interest: None declared

DOI: 10.1136/annrheumdis-2017-eular.6096

\section{AB1245-HPR NEW HEALTH TECHNOLOGIES AND LIFESTYLE MANAGEMENT FOR PATIENTS WITH OSTEOARTHRITIS}

M. Loiskandl $^{1}$, H. Ritschl ${ }^{2}$, T. Stamm ${ }^{1}$, G. Steiner ${ }^{1}$, J. Smolen ${ }^{1}$, D. Aletaha ${ }^{1}$. ${ }^{1}$ Rheumatology, Medical University of Vienna, Vienna; ${ }^{2}$ Joanneum, University of Applied Sciences, Graz, Austria

Background: Osteoarthritis $(\mathrm{OA})$ is one of the most common chronic diseases of the elderly worldwide. It represents significant impairments in terms of quality of life [1]. It notably affects self-care-tasks, body-image, self-esteem, well-being, social-activities and relationships. A wide-ranged field of therapy concepts exist. Medication is often one part, but it cannot solve other existing problems due to $\mathrm{OA}$ [2]. The demographic trends combined with the growth of mobile devices among the older population suggest that using digital devices, as a platform for interventions in health, may be a viable way forward and open new opportunities in healthcare [2].

Objectives: To $(A)$ analyse the literature to assistive devices and applications for $\mathrm{OA}$ patients and $(\mathrm{B})$ to evaluate existing health applications.

Methods: We performed a systematic literature review on this topic and explored existing mobile and web-based apps. The app findings were classified into those categories of the Activities of Daily Living Model, which were related to the impairments of $\mathrm{OA}$.

Results: We identified 6 studies, which contained relevant information. The main results showed, that there is interest and willingness to utilize mobile Health solutions [3]; a positive impact of web-based interventions; the benefit of online social support regarding the level of patient empowerment [4], self-management, lifestyle, physical activity [5] and self-efficacy [6]

The app exploration results in 16 web-based, 15 iOS and 9 Android applications. The areas most commonly found were disease- and treatment information $(n=23)$, forum, report, self-help groups $(n=16)$, self- and disease-management $(n=11)$, as well as nutrition tips $(n=8)$.

Conclusions: The recent years have seen a dramatic growth of digital applications. Also, the scientific interest has grown and numerous studies emphasise the power of these solutions to support OA patient in all areas of lifestyle management. Further research is necessary, to investigate the benefit of web-based or mobile applications for persons with OA.

References:

[1] T. Aigner, S. Söder, Typisierung, Graduierung und Stadieneinteilung der Osteoarthrose: Histopathologische Begutachtung der Gelenkdegeneration, Z. Für Rheumatol., 2008;67(1):32-40.

[2] J. Joe, G. Demiris, Older adults and mobile phones for health: A review, J. Biomed. Inform. 2013;46(5):947-954.

[3] S.J. Parker, S. Jessel, J.E. Richardson, M.C. Reid, Older adults are mobile too!ldentifying the barriers and facilitators to older adults' use of mHealth for pain management, BMC Geriatr. 2013;13(1):43.

[4] A. Allam, Z. Kostova, K. Nakamoto, P. J. Schulz, The Effect of Social Support Features and Gamification on a Web-Based Intervention for Rheumatoid Arthritis Patients: Randomized Controlled Trial, J. Med. Internet Res. 2015;17(1):e14.

[5] H. Umapathy, K. Bennell, C. Dickson, F. Dobson, M. Fransen, G. Jones, D.J. Hunter, The Web-Based Osteoarthritis Management Resource My Joint Pain Improves Quality of Care: A Quasi-Experimental Study, J. Med. Internet Res. 2015;17(7):e167.

[6] K.R. Lorig, P.L. Ritter, D.D. Laurent, K. Plant, The internet-based arthritis self-management program: A one-year randomized trial for patients with arthritis or fibromyalgia, Arthritis Rheum. 2008;59(7):1009-1017.

Disclosure of Interest: None declared

DOI: 10.1136/annrheumdis-2017-eular.6652

\section{AB1246-HPR INTRA ARTICULAR OZONE OR HYALURONIC ACID INJECTION: WHICH ONE IS SUPERIOR IN PATIENTS WITH KNEE OSTEOARTHRITIS? A 6-MONTH RANDOMIZED CLINICAL TRIAL}

S.A. Raeissadat ${ }^{1}$, S.M. Rayegani ${ }^{2}$, M. Moridnia ${ }^{3}$, S. Rahimi Dehgolan ${ }^{4}$ ${ }^{1}$ Physical Medicine and Rehabilitation Department, Shahid Modarres Hospital; ${ }^{2}$ Physical Medicine and Rehabilitation Department, Shohadaye Tajrish Hospital; ${ }^{3}$ Deputy of Education; ${ }^{4}$ Physical Medicine and Rehabilitation Department, Shahid Beheshti University of Medical Sciences, Islamic Republic Of

Background: Knee osteoarthritis $(O A)$ is a common disease with great burden through pain and decreased function (1). Except for knee replacement surgery as a definite treatment (2), there are many other therapeutic modalities including non-pharmacologic choices and some heterogeneous drugs like oral, topical and intra articular ones (3). Recent studies have showed promising results of ozone application in OA $(2,4-5)$.

Objectives: The aim of this study was to compare the effects of ozone therapy versus hyaluronic acid $(\mathrm{HA})$ intra articular injection in patients with knee $O A$.

Methods: This prospective RCT studied 174 patients in two random groups: ozone and HA. We performed three weekly injections of Hyalgan ${ }^{\circledR}$ versus $10 \mathrm{ml}$ of ozone solution in moderate knee OA patients. Participants were primarily evaluated and 6 months after injection using pain, stiffness and function questionnaires.

Results: No major adverse events were noted in the study. Total WOMAC score decreased in the ozone group from $40.8 \pm 9.8$ to $20.4 \pm 4.9(p<0.05)$ and in the HA group from $38.5 \pm 7.9$ to $17.1 \pm 4.2(p<0.05)$. A similar trend was observed in pain improvement according to VAS (table 1). Pain, stiffness and function significantly improved in both groups but no differences were found between groups.

Conclusions: Although both ozone and HA can be effectively used for improving function and reducing pain in selected patients with knee OA, neither of the two showed no superiority at 6 months follow up.

References:

[1] Richmond J, Hunter D, Irrgang J, et al. American Academy of Orthopaedic Surgeons clinical practice guideline on the treatment of osteoarthritis $(\mathrm{OA})$ of the knee. J Bone Joint Surg Am 2010; 92:990-993.

[2] Kr Mishra S, Pramanik R, Das P, Pratim Das PI. Role of intra-articular ozone

Abstract AB1244-HPR - Table 2. Self-reported fatigue and depression at baseline, after treatment and at 6 months follow-up

\begin{tabular}{|c|c|c|c|c|c|}
\hline Scale & Mean (SD) t1 & Mean (SD) t2 & Mean (SD) t3 & P-value diff ANOVA & Paired t-test T1-3 \\
\hline BRAF fatigue $\$$ & $13.89(5.4)$ & $10.85(4.9)$ & $9.46(5.8)$ & $\mathrm{p}>0.001$ & Diff $4.57(\mathrm{Cl}: 2.2 / 7.0)(\mathrm{p}>0.001)^{\star *}$ \\
\hline $\mathrm{PHQ}^{\#}$ & $25.13(5.9)$ & $20.67(6.8)$ & $18.25(7.1)$ & $p>0.001$ & Diff $6.44(\mathrm{Cl}: 4.0 / 8.9)(p>0.001)^{\star \star}$ \\
\hline VAS pain ${ }^{\dagger}$ & $45.54(24.4)$ & $39.08(21.1)$ & $36.9(23.0)$ & $p>0.241$ & Diff 7.64 (Cl:-1.4/16.7) ( $p>0.096)$ \\
\hline
\end{tabular}

${ }^{\$}$ BRAF (Bristol Rheumatoid Arthritis Fatigue Multi-Dimensional questionnaire) fatigue global score (0-30), \#PHQ-9 (Patient Health Questionnaire) depression score (0-70), ${ }^{\dagger}$ VAS pain (0-100).

Abstract AB1246-HPR - Table 1

\begin{tabular}{|c|c|c|c|c|c|c|}
\hline \multirow[t]{2}{*}{ Measure } & \multicolumn{2}{|c|}{ Ozone Therapy (Mean \pm SD) } & \multirow[t]{2}{*}{ Raw Mean Difference (SE) [95\% Cl] } & \multicolumn{2}{|c|}{ HA Therapy (Mean \pm SD) } & \multirow[t]{2}{*}{ Raw Mean Difference (SE) $[95 \% \mathrm{Cl}]$} \\
\hline & Before & After & & Before & After & \\
\hline VAS & $7.6 \pm 2.8$ & $2.6 \pm 2.0$ & $-5.0(0.2)[4.6-5.4]$ & $7.1 \pm 3.2$ & $3.0 \pm 2.4$ & $-4.1(0.15)[3.8-4.4]$ \\
\hline WOMAC Pain & $9.3 \pm 4.4$ & $3.2 \pm 1.6$ & $-6.1(0.2)[5.7-6.5]$ & $8.8 \pm 4.0$ & $2.9 \pm 1.6$ & $-5.9(0.2)[5.5-6.3]$ \\
\hline WOMAC Stiffness & $2.3 \pm 2.4$ & $1.1 \pm 1.6$ & $-1.2(0.05)[1.1-1.3]$ & $2.1 \pm 1.6$ & $1.1 \pm 0.8$ & $-1.0(0.05)[0.9-1.1]$ \\
\hline WOMAC Function & $29.2 \pm 7.0$ & $16.1 \pm 4.2$ & $-13.1(0.15)[12.8-13.4]$ & $27.6 \pm 6.6$ & $13.1 \pm 3.2$ & $-14.5(0.3)[13.9-15.1]$ \\
\hline WOMAC Total & $40.8 \pm 9.0$ & $20.4 \pm 5.0$ & $-20.4(0.2)[20.0-20.8]$ & $38.5 \pm 8.0$ & $17.1 \pm 4.2$ & $-21.4(0.2)[21.0-21.8]$ \\
\hline
\end{tabular}

